\title{
An Analysis Model for Knowledge Transfer Efficiency Based the Cultural Circumstances
}

\author{
Junfeng Jiang Xinghua Dang \\ School of Business Management, Xi'an University of Technology, Xi'an 710054, P. R. China
}

\begin{abstract}
This paper advances a model of knowledge transfer based on their cultural circumstances which are constructed from four dimensions whose characteristics are measured by a variable 'cultural distance' introduced. And the efficiency of knowledge transfer between the two enterprises is analyzed based on their cultural circumstances from time and cost. It concludes that the efficiency of knowledge transfer changes in an opposite direction to the change of cultural distance and that the distance of values between the two enterprises and the distance between their entrepreneurs' behavior play a prominent part in the efficiency of knowledge transfer.
\end{abstract}

Keywords: Cultural circumstance, Cultural distance, Knowledge transfer

\section{Introduction}

As a subset of 'culture', the enterprise culture bears the same effect. An enterprise's culture is formed by traditions and customs while an enterprise's culture includes the enterprise's values, i.e., values that can define the enterprise's activities and behavioral patterns. Japanese scholars argue that enterprise management should also be a culture - a particular culture that contains its own values, believes and language. On the other hand, the scholars who hold the theory 'concentric circles' think that the enterprise culture is made up of four concentric circles as shown in Figure 1.

Knowledge has been the most strategic resource for an enterprise (Nonaka, 1994; Grant, 1996; Simonin, 1999) [1]-[3], and in order to make it more valuable, the enterprise has to be able to identify, create and continuously manage its knowledge (Duane, et al, 2000) [4]. What's more, an enterprise's ability to explore, maintain and cultivate its competitive advantage is determined largely by the whole enterprise's ability to create, expand and apply its knowledge (Drucker, 1999; Hoopes and Postrel, 1999 ) [5]-[6]. Therefore, how to internalize an enterprise's external knowledge and create value out of it has become a crucial issue to modern enterprises.

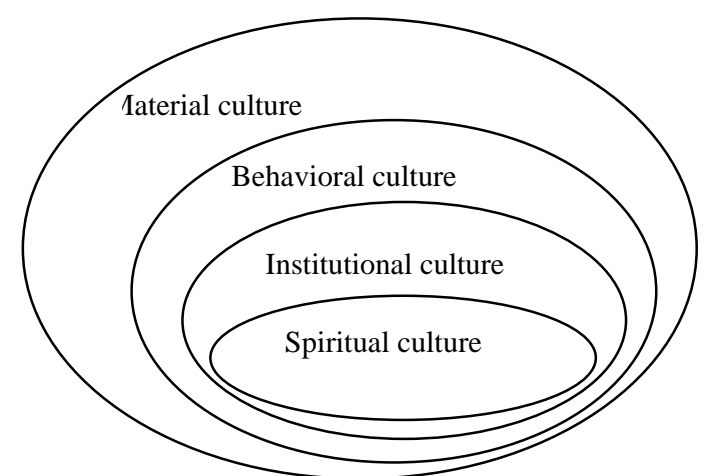

Fig. 1: The system construction for the enterprise's culture.

Research shows that there are four factors that can influence the cross-organizational knowledge transfer knowledge, knowledge source, knowledge recipient and the distance between knowledge source and knowledge recipient. Meanwhile, knowledge itself is divided into three dimensions - simple versus complex, explicit versus tacit, and independent versus systematic (Garud,R. \& Nayyar, P.R.1994) [7] while knowledge source and knowledge recipient are formed by knowledge possessor, means for knowledge transfer and ways for knowledge spread (People, Tool and Routines). The rate of success in knowledge transfer correlates positively with the articulability of knowledge source while negatively with the depth of knowledge embedment, and positively with the favorable learning culture of the knowledge recipient while negatively with the priority of the items (Jeffrey L.Cummings \& Bing-Sheng Teng., 2003) [8]. Further research probes the effect of the distance of knowledge transfer on knowledge transfer, and holds that the distance of knowledge transfer is made up of knowledge distance, cultural distance and space distance (Rabi S.Bhagat \& Ben L.Kedia.2002). On the other hand, some scholars try to make researches on the efficiency of knowledge transfer from such three dimensions as the receiver's social capital in terms of its structural characteristics, relation characteristics, and knowledge itself (Daniel Z.Levin, 2004) [9]. However, it is clear that recent research deals mainly with the effect of the characteristics of knowledge itself on knowledge transfer and lays emphasis on the point that the biggest obstacle to the effectiveness of knowledge transfer is the tacit ness and ambiguity of 
knowledge. Moreover, though the question of knowledge transfer resulted from different cultural patterns has been recognized, it lacks further treatment.

This thesis constructs an enterprise's cultural circumstance from such four dimensions as spiritual culture, institutional culture, behavioral culture and material culture, and, for the sake of argument, divides knowledge into localized and non-localized knowledge from a unique angle. Then it advances a model of knowledge transfer between two enterprises based on different cultural circumstances and analyzes the correlation between knowledge transfer and culture by introducing a variable 'cultural distance', and makes authentic proofs over the statistics obtained by a survey and research, proving the hypothesis of the relation between the efficiency of knowledge transfer and the cultural distance between the two enterprises.

\section{A Model of Knowledge Transfer for analyzing the cultural circumstance}

The most basic model to describe knowledge transfer is the communication model advanced by Szulanski et al in 1996 [10]. Although the communication model is introduced to describe the process of knowledge transfer between individuals, it can also be expanded into knowledge transfer between two enterprises. It is safe to say that knowledge transfer is a process of information spread from knowledge's source unit (Enterprise A) to its recipient unit (Enterprise B), which can be divided into four stages, as is shown in Figure 2. The first stage is the starting-stage whose main task is that the source unit of knowledge (Enterprise A) identifies the knowledge embedded in the cultural circumstances that satisfies the counterpart's needs. The second stage is an implementing stage during which the two parties build situational channels suitable for knowledge transfer, and the source unit of knowledge (Enterprise A) adjusts the knowledge transferred to the needs of the recipient unit of knowledge (Enterprise B), that is, an 'encoding' process. Accordingly, the third stage is a 'decoding' process, namely, an adjusting stage whose main task is that the recipient unit of knowledge (Enterprise B) adjusts the knowledge transferred to the new circumstance. The fourth and last stage is a conforming stage during which the recipient unit of knowledge (Enterprise B) changes the knowledge transferred into part of its own knowledge via institutionalization (See figure 2).

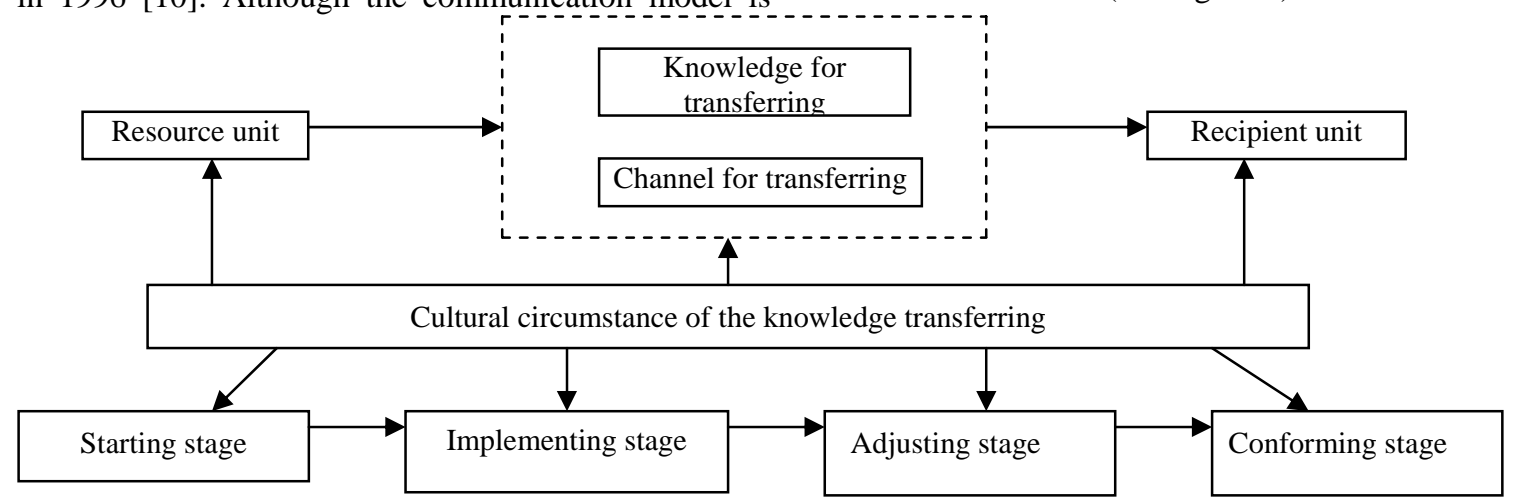

Fig. 2: The relationship between the communication mode of knowledge transferring and the culture circumstance.

It is worth noting that in the communication model, Szulanski stresses that knowledge transfer occurs in certain circumstance, therefore, for the sake of argument over the relationship between knowledge transfer between two enterprises and their cultural circumstances, this thesis applies the communication model to the analysis of the relationship between knowledge transfer between two enterprises and the factor cultural circumstance.

\subsection{The division of an enterprise's dimensions in terms of its cultural circumstance}

In view of the above-mentioned classification of the word 'culture', an enterprise's culture is to be defined in the way the school 'concentric circles' does, that is, the enterprise's spiritual culture, institutional culture, behavioral culture and material culture as a whole. Accordingly, the cultural circumstance can be divided into four dimensions. This thesis makes a further division of the four dimensions - spiritual culture, institutional culture, behavioral culture and material culture, and the main content contained in each dimension is shown in Table 1. 


\begin{tabular}{|c|c|}
\hline Culture circumstance dimensions & \multicolumn{1}{|c|}{ Context } \\
\hline spiritual culture & Philosophy of enterprise/Enterprise values /Spirit of enterprise \\
\hline institutional culture & Institution of organization \\
\hline behavioral culture & Enterprises behavior(entrepreneurs, employees)/ Interpersonal relationship \\
\hline material culture & product or service / circumstance of enterprise \\
\hline
\end{tabular}

Table 1: The division of the four dimensions for the enterprise's culture.

\subsection{The division of knowledge type based on different cultural circumstances}

Garud, R., \&Nayyar, P.R. (1994) analyzes the three pairs of knowledge's dimensions - simple versus complex, explicit versus tacit, and independent versus systematic. These three pairs of dimensions show clearly the properties of knowledge itself, but the fact that the knowledge an enterprise possesses is a complex system has brought great difficulty to the study on knowledge transfer between two enterprises, and it does not favor the development of this thesis. Unlike Garud, R., \&Nayyar, P.R., Hayek introduces the concept 'local information /knowledge' into the division of knowledge from a different angle of view, and maintains that any type of knowledge is local knowledge. For one thing, this thesis focuses its study on the knowledge to be transferred between two enterprises, for another, as for different enterprises, their cultures are remarkably different from each other, their understanding of 'knowledge' will not conform to each other, either [11] - [12].

Based on Hayek's theoretical foundation, this thesis interprets the word 'local' by means of the scope of circumstance formed by the enterprise's culture. By this means, knowledge is divided into localized knowledge and non-localized knowledge, the former referring to the knowledge the enterprise has already possessed, though its content is not necessarily exclusive to this enterprise, while the latter to the knowledge the enterprise does not then possess. By such definitions, the knowledge that needs to be transferred is confined to a certain enterprise. On the other hand, based on the above-mentioned division of knowledge, the knowledge the enterprise uses to transfer to the recipient unit or that the enterprise has already received (or the enterprise is prepared to receive) is called a knowledge pack. It can be seen that the knowledge pack is formed by the interaction among the above-mentioned four dimensions of the cultural circumstance. The scope of the enterprise's cultural circumstance is defined by the diamond shown in
Figure 3, each of whose four vertices stands for a dimension of the cultural circumstance. The knowledge that needs to be transferred falls right within the scope of the cultural circumstance, forming a knowledge pack which includes the knowledge the enterprise possesses and applies then. See Figure3 below.

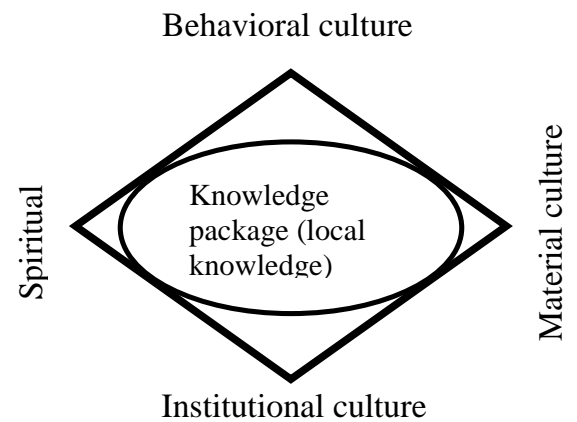

Fig. 3: Cultural circumstances of knowledge.

\subsection{A model of knowledge transfer based on cultural circumstances}

The knowledge any enterprise possesses will fall within the scope of certain cultural circumstance that is formed by the four dimensions. Thus in the light of different cultural circumstances, knowledge still needs to be divided into localized and non-localized knowledge even if its content is given. Although knowledge transfer itself indicates that the localized knowledge is transferred from a certain cultural circumstance to a new one, yet the scope of the new cultural circumstance won't, as a rule, be in conformity with the knowledge transferred. If the two enterprises' dimensions are similar to a certain extent as regards their cultural circumstances, there will appear some overlap between the two scopes of the two cultural circumstances. Furthermore, with the increase in the similarity between the dimensions of the two cultural circumstances, there will be more and more overlap between the scopes of the two cultural circumstances. When the knowledge to be transferred happens to fall within the overlapping area formed by the two scopes of the source unit's and the recipient unit's cultural 
circumstances, the knowledge transfer will be relatively low in efficiency (Szulanski, 1996). On the other hand, when the knowledge to be transferred falls within the scope of the source unit's cultural circumstance but outside the scope of the recipient unit's cultural circumstance, it needs substantial adjustment when it is transferred. Only in this way can the knowledge to be transferred adapt to the recipient unit's cultural circumstance, thus improving the efficiency of knowledge transfer (See Figure 4).

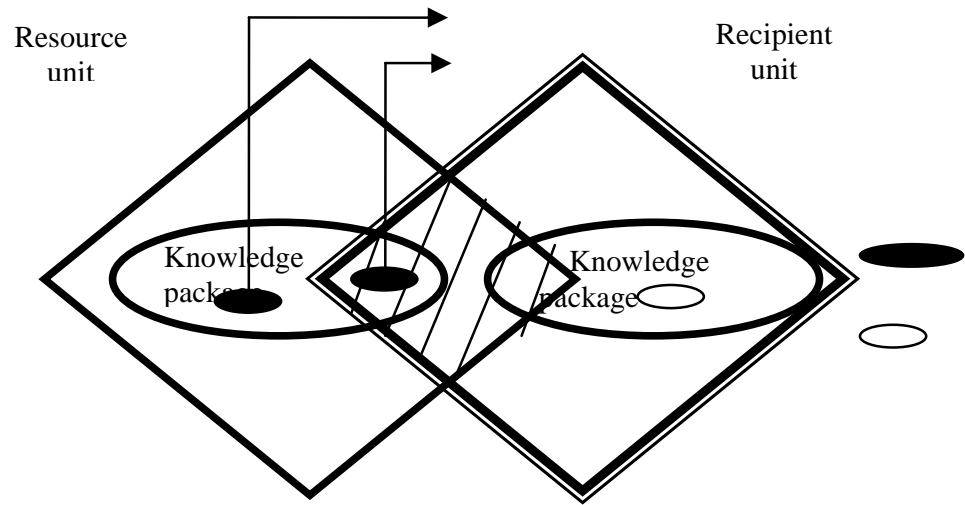

Local knowledge to transfer of resource unit

Non-local knowledge received of recipient unit

Fig.4: Mode for knowledge transferring

\section{Analysis of the transfer efficiency of knowledge based on cultural circumstances}

\subsection{The Effect of Cultural Distance}

The above analysis shows that the efficiency of knowledge transfer has much to do with the enterprises' difference in the scope of their cultural circumstances. Accordingly, this thesis introduces the concept 'cultural distance' to describe the difference between two enterprises in the scope of their cultural circumstances when studying the efficiency of knowledge transfer between them.

The concept 'cultural distance' is used as a variable to describe the degree of difference between two cultures and is widely used by scholars when they make researches on foreign direct investment (FDI). When it is introduced to study the knowledge transfer between two enterprises, it refers generally to the degree of difference in values between the two enterprises (Williams et al. 1998) [13]. Williams (1984) also notices that cultural distance is an important factor that obstructs the knowledge transfer between two enterprises [14]. Shenkar ( 2001 ) concludes in his paper that the greater the cultural distance is, the less efficient the knowledge transfer will be, the proof of which is also offered in that paper [15]. Similarly, Johansson and Vahlen ( 1977 ) think that cultural distance is the most basic factor that obstructs an enterprise's information exchange with its partner [16], and
Simonin ( 1999 ) thinks that it is necessary to take cultural distance into consideration when studying the process of knowledge transfer, because it is the greatest obstacle to either of the two enterprises' understanding of its partner's knowledge [17].

To sum up, the relationship between the knowledge transfer and cultural distance is illustrated in this thesis by the knowledge transfer described in the model of knowledge transfer, as is shown in Figure 4. And the greater the cultural distance between the two enterprises is, there will be less overlap between the two enterprises regarding their scope of cultural circumstance.

\subsection{Analysis of the Transfer Efficiency}

The process of knowledge transfer between two enterprises under different cultural circumstances should be - first, the source unit identifies the knowledge needed by the recipient unit from its localized knowledge; then the source unit encodes the localized knowledge (unlike a computer's encoding) and forms a knowledge pack, which brings greater efficiency to the knowledge transfer. As for the study on the importance of 'encoding', Schulz et al. (2001) point out that the aim of the enterprise's 'encoding' the knowledge to be transferred, thus forming a knowledge pack in a specific form, is for the effectiveness of knowledge transfer [18]. Davenport et al. (1998) think that 'encoding' enables the knowledge to be understood more easily and insures that the knowledge keeps its original meaning during the process of 
knowledge transfer. Schulz et al. (2001) say in their paper that there are many types of 'encoding', for example, the knowledge may be expressed by a report or be written into a relevant document, or be illustrated in a training class.

In order to facilitate the recipient unit's receiving knowledge accurately and promptly during the process of 'encoding', the source unit must take the recipient unit's culture into consideration. And if there is a considerable cultural distance between the two enterprises, it will take the source unit substantial time and cost to encode the knowledge to be transferred. On the contrary, if the cultural distance between the two enterprises is fairly short, all the source unit needs to do may be change the knowledge into a knowledge pack and transfer it directly to the recipient.

When the recipient unit receives the knowledge pack, first of all, it has to organize some resources of manpower and material and spend some time to identify the knowledge received and see if the knowledge meets its needs. Then, what affects most the time and cost needed in the knowledge transfer is the process of 'decoding'. So if the recipient unit has to spend lots of time to understand the knowledge when the knowledge is transferred to it, it will go against. Besides, the cost of investment incurred will be a large sum, which goes surely against the wishes of the two parties. Furthermore, either of the two aspects whether the source unit can understand correctly the questions raised by the recipient unit and whether the recipient unit can understand correctly the explanations offered by the source unit - is affected by the cultural distance: if it is a short cultural distance, the two enterprises will find it easy to understand each other; if it is a long distance, they may find it impossible to communicate.

At last, the recipient unit has to make some necessary adjustment to the knowledge transferred, in an effort to adapt the knowledge transferred to the enterprise's culture and integrate it with the enterprise's existing knowledge, thus forming in the end the so-called 'effective knowledge' that can promote the enterprise's output. To change the knowledge transferred into its effective localized knowledge, the recipient unit needs to absorb the knowledge, which requires a systematic learning and research of the relevant departments so that the knowledge will be applied effectively in the whole enterprise.

\subsection{Relevant hypotheses}

The above analysis shows that the efficiency of knowledge transfer between two enterprises is a function of their cultural distance, and this relationship can be expressed by the formula below:

$$
E=f\left(d_{1}, d_{2}, d_{3}, d_{4}\right)
$$

In the above formula, $E$ refers to the efficiency of knowledge transfer between two enterprises, $d_{1}$ to the distance of spiritual culture between the two enterprises, $d_{2}$ to the distance of institutional culture between the two enterprises, $d_{3}$ to the distance of behavioral culture between the two enterprises, and $d_{4}$ to the distance of material culture between the two enterprises.

Generally, the shorter the cultural distance is, the more overlap there will be between two enterprises with regard to the scope of their cultural circumstance, and the higher efficiency there will be in knowledge transfer when the localized knowledge is transferred into the scope of a new cultural circumstance. Accordingly, there will be a large overlap between their knowledge. In this case, the localized knowledge transferred from the source unit might have been contained in the knowledge the recipient unit is applying. Consequently, the efficiency of knowledge transfer will be greatly reduced. Therefore, there ought to be a minimum cultural distance (marked $d_{\text {min }}$ ) between two enterprises when they conduct a knowledge transfer. On the other hand, if the cultural distance between the two enterprises is too long, the chance of their knowledge transfer will be slim. In case it does occur, it would take them too much cost as well as time. For example, a knowledge transfer is quite unlikely to occur between a computer manufacturer and a toothpaste manufacturer. For the sake of argument, this thesis is confined to the case in which the cultural distance between the two enterprises is not very long. Therefore, there also ought to be a maximum cultural distance (marked $d_{\max }$ ) between two enterprises when they conduct knowledge transfer.

Therefore, in case of a knowledge transfer between two enterprises, we must satisfy the prerequisites thereinafter as regards their cultural distance:

$$
d=\left\{d_{1}, d_{2}, d_{3}, d_{4}\right\}
$$

In which:

$$
\left\{\begin{array}{l}
d_{1} \in\left[d_{1 \min }, d_{1 \max }\right] \\
d_{2} \in\left[d_{2 \min }, d_{2 \max }\right] \\
d_{3} \in\left[d_{3 \min }, d_{3 \max }\right] \\
d_{4} \in\left[d_{4 \min }, d_{4 \max }\right]
\end{array} .\right.
$$

For the sake of argument, this thesis standardizes the expression of $d_{i \text { min }}, d_{2 \text { min }}, d_{3 \min }, d_{4 \text { min }}$ as ' 0 ' while $d_{i \max }, d_{2 \max }, d_{3 \max }, d_{4 \max }$ as ' 1 '. Thereby $d \in[0,1]$.

Under the condition $d \in[0,1]$, this thesis puts forward such hypotheses as below: 
H1: the shorter the distance of spiritual culture between two enterprises is, the higher efficiency there will be in their knowledge transfer;

H2: the shorter the distance of institutional culture between two enterprises is, the higher efficiency there will be in their knowledge transfer;

H3: the shorter the distance of behavioral culture between two enterprises is, the higher efficiency there will be in their knowledge transfer;

H4: the shorter the distance of material culture between two enterprises is, the higher efficiency there will be in their knowledge transfer.

To get a clearer understanding of the determinative factor 'cultural circumstance' in the knowledge transfer, this thesis gives expression of the cultural distance in the way below according to the theory 'concentric circles':

$$
\left\{\begin{array}{l}
d_{1}=a_{11} d_{11}+a_{12} d_{12}+a_{13} d_{13} \\
d_{2}=d_{21} \\
d_{3}=a_{31} d_{31}+a_{32} d_{32} \\
d_{4}=a_{41} d_{41}+a_{42} d_{42}
\end{array}\right.
$$

Of the above, $d_{11}$ refers to the philosophic distance between the two enterprises, $d_{12}$ to the distance between their values, $d_{13}$ to the distance between their spirits, $d_{21}$ to the distance between their institutions, $d_{31}$ to the distance between their behaviors, $d_{32}$ to the distance between their interpersonal relationships, $d_{41}$ to the distance between their products or service, and $d_{42}$ to the distance between their environments. And $a_{11}, a_{12}, a_{13}$ refers respectively to the proportion of the distance between their philosophies to that between their values and that between their spirits in the distance between their spiritual cultures, $a_{31}, a_{32}$ respectively to the proportion of the distance between their behaviors to that between their interpersonal relationships in the distance between their behavioral cultures, and $a_{41}, a_{42}$ respectively to the proportion of the distance between their products or service to that between their environments in the distance between their material cultures. Then we have:

$$
E=f\left\{\left(d_{11}, d_{12}, d_{13}\right), d_{21},\left(d_{31}, d_{32}\right),\left(d_{41}, d_{42}\right)\right\}
$$

As for the question as which dimension of the enterprise's culture is the most important one in knowledge transfer, it is commonly accepted in the management science circle that values is the key to the enterprise's culture. What constitutes our values is the ideology that leads our awareness to choose certain behaviors to make the necessary material and spiritual products come into being. Therefore we can see that the deep-rooted values provide a yardstick to measure the cohesive forces. Such a mutual system of rules and a standard measure of assessment determine the entrepreneur's behavioral tendency as a whole. In fact, if an enterprise lacks a clear measure of its values, or its values are inaccurate, the chance of its success will be rather slim. Allen Kennedy also point out that for the enterprises that hold the same values, their common values determine their basic features, which makes them unique to others.

Besides, some scholars notice that the entrepreneur's behavior can also determine the enterprise's future. What the successful enterprises have experienced tells us that a good entrepreneur means a half story of the enterprise's success. This is because both the enterprise's style and behavior of decision-making originate from its entrepreneur, who, like the strategist or the commander in a troop, plays a dominant role in running the enterprise. Just like a false war, a false decision will only turn out to be a failure. Therefore, the entrepreneur's behavioral culture is also important in the enterprise's whole culture.

So if we want to maximize the efficiency of knowledge transfer, we must have: $d_{12}=0, d_{31}=0$, or:

$$
E=f\left\{\left(d_{11}, 0, d_{13}\right), d_{21},\left(0, d_{32}\right),\left(d_{41}, d_{42}\right)\right\}
$$

Based on the above analysis, this thesis puts forward another two hypotheses:

H5: the distance of values between two enterprises has a prominent effect on the efficiency of knowledge transfer between them;

H6: the distance of the entrepreneur's behavior between two enterprises has a prominent effect on the efficiency of knowledge transfer between them.

\section{Analysis of Authentic Proof}

To see whether the hypotheses mentioned above are tenable or not, we did extensive and careful survey and research on over 150 enterprises located in Xi'an High-tech Development Zone during the period from July to October in the year 2005. We obtained from them a great deal of data on knowledge transfer between different enterprises through an extensive collection of the statistics we need. The survey and research was carried out in the form of questionnaire. When designing the factor-measuring indexes, we conform mainly to the following principles: (1) Try to select as far as it is allowed the indexes of measure that have been used in related literature and make proper modifications to them when necessary; (2) If the appropriate indexes are not available in the related literature, then design relevant indexes by summing up the theoretical analysis of the factor in the literature. Moreover, all the factors designed in this thesis are measured by Seven-point Likert Scale. 
According to the attributes of the questions in the questionnaire, this thesis chooses the multivariate regression analysis as the method of authentic proof. In this regression, the dependent variable is the efficiency of knowledge transfer between two enterprises while the independent variable is the degree of the cultural distance between the two enterprises, or the four distances in their spiritual, institutional, behavioral and material cultures. The result of the regression analysis, realized via the SPSS software, is shown in Table 2.

\begin{tabular}{|c|c|c|c|c|c|c|}
\hline Item & Variable & $\begin{array}{c}\text { Non standardized } \\
\text { regression coefficient }\end{array}$ & Std. Error & $\begin{array}{c}\text { standardized regression } \\
\text { coefficient }\end{array}$ & $\mathrm{T}$ & $\begin{array}{c}\text { significan } \\
\mathrm{t}\end{array}$ \\
\hline 1 & (Constant) & 7.724 & .264 & & 29.274 & .000 \\
\hline 2 & Dis of sprit & -.312 & .053 & -.406 & -5.877 & .002 \\
\hline 3 & Dis of institution & -.192 & .098 & -.215 & -2.966 & .006 \\
\hline 4 & Dis of behavior & -.270 & .072 & -.306 & -3.754 & .013 \\
\hline 5 & Dis of material & -.157 & .096 & -.203 & -1.641 & .162 \\
\hline
\end{tabular}

Table 2: Result of the regression.

Judging from the standardized regressive coefficients obtained, the first four hypotheses in this thesis are all proved. The following three distances between the two enterprises - distances between their spiritual, institutional, and behavioral- will affect the effectiveness of the knowledge transfer between the two enterprises. But material cultures distance does not affect the effectiveness of the knowledge transfer. And the longer the distances between these cultures are the less effective the knowledge transfer will be. In addition, we can see from the standardized regressive coefficients that of the cultures, the degree of distance in spiritual culture exerts the greatest influence on the effectiveness of the knowledge transfer between two enterprises.

And in order to prove hypotheses 5 and 6, this thesis analyzes the factors that affect the distance of spiritual culture and that of behavioral culture by regression. The detailed results are shown in Table 3 and 4.

\begin{tabular}{|c|c|c|c|c|c|c|}
\hline Item & Variable & $\begin{array}{c}\text { Non standardized } \\
\text { regression coefficient }\end{array}$ & Std. Error & $\begin{array}{c}\text { standardized regression } \\
\text { coefficient }\end{array}$ & $\mathrm{T}$ & significant \\
\hline 1 & (Constant) & -.599 & .594 & & -1.007 & .000 \\
\hline 2 & Philosophy of enterprise & .243 & .225 & .286 & 3.078 & .322 \\
\hline 3 & Enterprise values & .465 & .236 & .473 & 2.966 & .097 \\
\hline 4 & Spirit of enterprise & .256 & .128 & .303 & 2.188 & .091 \\
\hline
\end{tabular}

Table 3: Result of the regression.

\begin{tabular}{|c|c|c|c|c|c|c|}
\hline Item & Variable & $\begin{array}{c}\text { Non standardized } \\
\text { regression coefficient }\end{array}$ & Std. Error & $\begin{array}{c}\text { standardized regression } \\
\text { coefficient }\end{array}$ & $\mathrm{T}$ & significant \\
\hline 1 & (Constant) & $-7.580 \mathrm{E}-02$ & .560 & & -.135 & .000 \\
\hline 2 & $\begin{array}{c}\text { Enterprises behavior } \\
\text { (entrepreneurs, employees) }\end{array}$ & .489 & .133 & .605 & 3.679 & .008 \\
\hline 3 & Interpersonal relationship & .430 & .169 & .418 & 2.544 & .038 \\
\hline
\end{tabular}

Table 4: Result of the regression.

It can be seen from the results of the regression analysis that the factor the two enterprises' values exerts the greatest influence on the distance between their spiritual cultures, and that the entrepreneur's behavior has the most prominent effect on the enterprise's behavioral culture. But the affect of the philosophy of enterprise is not significant. Therefore, we can conclude that an enterprise's values and its entrepreneur's behavior play a prominent part in the efficiency of its knowledge transfer with others, thus proving the last two hypotheses.

\section{Conclusions and Outlook}

This study concludes that knowledge transfer is built on certain cultural circumstance, and it establishes a model of knowledge transfer. Further, it analyzes the effect of the distance between two enterprises' cultures on their knowledge transfer from angles of time and cost, and it draws two conclusions thereinafter:

1) When knowledge transfer occurs between two enterprises, the efficiency of knowledge transfers changes in the opposite direction to the change of their cultural distance;

2) Of the factors within the category of cultural distance, values in the spiritual culture and the entrepreneur's behavior in the behavioral culture play 
the most prominent part in the efficiency of knowledge transfer.

Although this thesis researches into the efficiency of knowledge transfer under cultural circumstance, yet it deals with knowledge transfer only between two enterprises, not considering the question of knowledge transfer among multiple enterprises. When there are more than two enterprises involved and some enter into an alliance, there will arise lots of new problems for knowledge transfer. In this case, it will be more difficult to conduct a knowledge transfer.

\section{Acknowledgement}

This research was supported by the National Natural Science Foundation of China under Grant 70672089 and Special Research Fund for the Doctoral Program of Higher Education under Grant 20050700009 and Excellent Doctoral Fund of Xi'an University of Technology.

\section{References}

[1] I. Nonaka, A dynamic theory of organizational knowledge creation. Organization Science, 5: 14-37, 1994.

[2] R.M. Towanla and Grant, Knowledge-based theory of the firm. Strategic Management Journal, 17: 109-122, 1996.

[3] B. Simonin, Transfer of Marketing Know-How in International Strategic Alliances: An Empirical Investigation of the Role and Antecedents of Knowledge Ambiguity. Journal of International Business Studies, 30: 463-490, 1999.

[4] A.R. Duane and H.U. Lee, Technological learning management, firm growth and performance: an introductory easy, Journal of engineering and Technology Management, 17: 231-246, 2000.

[5] P.F. Drucker, Mangement challenges for the 21st Century .Harper Business, New York, 1999.

[6] D. Hoopes, and G. S. Potrel, Shared knowledge, "glitches" and product development performance, Strategic Management Journal, 20:837-865, 1999.

[7] R. Garud and P.R. Nayyar, Transformative capacity: Continual structuring by inter-temporal technology transfer. Strategic Management Journal, 15:365-385, 1994.

[8] L. Cummings and B.SH. Teng, Transferring R\&D Knowledge: the key factors affecting knowledge transfer success. Journal of England Technology Management, 20:39-68, 2003.

[9] Z. Levin, The Strength of Weak ties You Can trust: the Mediating Role of Trust in Effective
Knowledge Transfer. Management Science, 50: 1477-1490, 2004.

[10] Szulanski, Exploring internal stickiness: Impediments to the transfer of best practice within the firm. Strategic management journal, 17:27-43, 1996.

[11] U. Zander and B. Kogut, Knowledge and the speed of the transfer and imitation of organizational capabilities. Organization Science, 6:76-92, 1995.

[12] Y. Wang and G.SH. Liu, Study on the Cause and Transferring Mechanism of Stiff Knowledge in Case of Cooperation in Production, Learning and Research. Scientific Research Management, 6: 114-121, 2001.

[13] D. William, 'Z' theory: how the U.S.A to face the challenge from Japan. Peking: Social Science Press, pp.155-158, 1984.

[14]D. Williams, S.L. Han and W.J. Qualls, A Conceptual Model and Study of Cross-Cultural Business Relationships. Journal of Business Research, 42:135-143, 1998.

[15] O. Shenkar, Cultural Distance Revisited: Towards a More Rigorous Conceptualization and Measurement of Cultural Differences. Journal of International Business Studies, 32:519 -535, 2001.

[16] J. Johansson and J.E Ahlen, The internationalization process of the firm: A model of knowledge development and increasing foreign market commitments. Journal of International Business Studies, 8:23 - 32, 1997.

[17] B. Simonin, Ambiguity and process of knowledge transfer alliances. Strategic Journal, 20:595-623, 1999.

[18] M. Schulz and L.A. Jibe, Codification and tacit ness as knowledge management strategies: an empirical exploration. Journal of High Technology Management Research, 12:139 -165, 2001. 